\title{
Estrutura representacional de profissionais da estratégia de saúde da família sobre violência intrafamiliar contra idosos
}

\section{Family health strategy personnel's representational structures regarding domestic violence against older adults}

\section{Estructura de representación de profesionales de la estrategia de salud de la familia sobre la violencia intrafamiliar contra los ancianos}

\author{
Elisama Nascimento Rocha'; Alba Benemérita Alves Vilelal'; Denize Cristina de OliveiraIII; \\ Doane Martins da Silva ${ }^{I V}$; Marta dos Reis Alves ${ }^{V}$; Saulo Sacramento Meira ${ }^{V I}$
}

\begin{abstract}
RESUMO: O estudo objetiva analisar a estrutura representacional de profissionais de saúde acerca da violência intrafamiliar contra idosos. Pesquisa descritiva, exploratória, de natureza qualiquantitativa, desenvolvida entre maio e julho de 2012, com suporte na perspectiva estrutural da Teoria das Representações Sociais. Participaram 81 profissionais atuantes em 16 unidades de saúde da família (USF), de Jequié-Bahia. Utilizou-se a evocação livre de palavras e a entrevista semiestruturada na coleta dos dados. As evocações foram processadas pelo software EVOC 2003 e as entrevistas foram submetidas à análise de conteúdo temática. A estrutura representacional mostrou-se caracteristicamente negativa, sustentada por dimensões que retratam o enfrentamento dos profissionais diante das práticas de violência intrafamiliar contra idosos, identificadas no cotidiano de trabalho das USF. O conhecimento desta representação possibilita um direcionamento aos profissionais e gestores na elaboração de estratégias de promoção e prevenção no contexto familiar e social.
\end{abstract}

Palavras-Chave: Violência; família; idoso; profissionais de saúde.

\begin{abstract}
Conducted from May to July 2012, this exploratory, quali-quantitative, descriptive study drew on the structural approach to Social Representations Theory to examine health professionals' representational structures regarding domestic violence against older adults. The study participants were 81 professionals from 16 family health care facilities in Jequié, Bahia State, Brazil. Data was collected by the technique of free evocation of words, and semi-structured interview. Evocations were analyzed using EVOC 2003 software, and the interviews were analyzed using thematic content technique. The representational structures identified were characteristically negative, underpinned by dimensions that shows professionals' confrontation of domestic violence against the elderly identified at Family Health Care facilities. Knowledge of these representations gives professionals and managers a sense of direction in developing strategies for promotion and prevention in the family and social contexts. Keywords: Violence; family; older adults; health professionals.

RESUMEN: El estudio tiene como objetivo analizar la estructura de representación de profesionales de la salud sobre la violencia doméstica contra los ancianos. Investigación descriptiva, exploratoria, de naturaleza cualitativa y cuantitativa, Ilevada a cabo entre mayo y julio de 2012, con el apoyo desde la perspectiva estructural de la Teoría de las Representaciones Sociales. Asistieron 81 profesionales que trabajan en 16 de las Unidades de Salud de la Familia (USF) de Jequié-Bahia. Se utilizó el recuerdo libre de palabras y entrevistas semiestructuradas para recopilar datos. Evocaciones fueron procesadas por EVOC 2003 y las entrevistas fueron sometidas a un análisis de contenido temático. La estructura representacional mostró características negativas, sustentada por dimensiones que muestran el enfrentamiento de los profesionales ante las prácticas de violencia intrafamiliar contra ancianos, identificados en el trabajo diario de las USF. El conocimiento de esta representación nos permite referirnos a profesionales y directivos en la elaboración de estrategias de promoción y prevención en el contexto familiar y social.

Palabras Clave: Violencia; familia; anciano; profesionales de la salud.
\end{abstract}

\section{INTRODUÇÃO}

O envelhecimento populacional é, hoje, um fenômeno mundial. Nessa perspectiva, na realidade brasileira, em 1940, a população idosa representava
$4,1 \%$ da população total, e passou a representar $12,1 \%$ em 2011. Sendo assim, o contingente, em valores absolutos, aumentou de 1,7 milhão para cerca de 23,5

IEnfermeira. Mestre em Enfermagem pelo Programa de Pós-Graduação em Enfermagem e Saúde da Universidade Estadual do Sudoeste da Bahia. Jequié, Bahia, Brasil. E-mail: elisamapq@hotmail.com.

IIEnfermeira. Doutora em Enfermagem. Professora Adjunta do Curso de Graduação em Enfermagem da Universidade Estadual do Sudoeste da Bahia. . Jequié, Bahia, Brasil E-mail: albavilela@gmail.com.br.

IIIEnfermeira. Doutora em Saúde Pública. Professora Titular do Programa de Pós-Graduação em Enfermagem da Universidade do Estado do Rio de Janeiro. Rio de Janeiro, Brasil. E-mail: dcouerj@gmail.com.

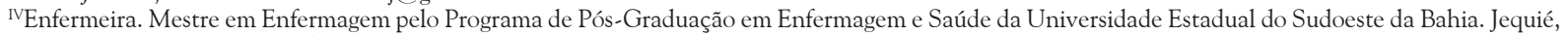
Bahia, Brasil E-mail: doane.ef@hotmail.com.

VEnfermeira. Mestre em Enfermagem pelo Programa de Pós-Graduação em Enfermagem e Saúde da Universidade Estadual do Sudoeste da Bahia. Jequié, Bahia, Brasil E-mail: martareisalves@yahoo.com.

VIFisioterapeuta. Mestre em Enfermagem pelo Programa de Pós-Graduação em Enfermagem e Saúde da Universidade Estadual do Sudoeste da Bahia. Jequié, Bahia, Brasil E-mail: saulo_meira@hotmail.com. 
milhões no mesmo período. Desse modo, observa-se uma tendência demográfica em curso desde os anos 1970: mudanças expressivas na estrutura etária da população, no sentido de seu envelhecimento. Isso se traduz, em parte, no envelhecimento das famílias, acarretando mudanças, onde estima-se que 9 milhões de idosos brasileiros moram na casa de filhos, genros ou outros parentes ${ }^{1}$.

Assim, destaca-se que o envelhecimento populacional gera novas demandas aos serviços de saúde, na medida em que aumenta o número de usuários idosos em qualquer que seja o nível de complexidade².

Em sua maioria são idosos dependentes, que buscam a ajuda de familiares para lidar com suas dificuldades nas atividades do cotidiano e/ou de renda. Dessa maneira, representam possíveis vítimas de violência familiar e potenciais demandantes de uma política de cuidados ${ }^{1}$.

A violência intrafamiliar contra idosos engloba qualquer tipo de relação de abusoparaticado no contexto privado da família contra esse grupo. Esta pode ser de natureza física, psicológica, financeira, sexual ou material, repercutindo na qualidade de vida do idoso ${ }^{3}$. Por sua vez, representa um grande desafio para a sociedade em geral, e particularmente para o setor saúde, visto que, provoca, além de óbitos, traumas físicos e emocionais, o que cria uma demanda cada vez maior por serviços de saúde ${ }^{4}$.

Diante disso, a unidade de saúde da família (USF), porta de entrada do sistema local de saúde e composta por uma equipe multiprofissional, tem a responsabilidade de assumir o acompanhamento permanente e sistemático de um número determinado de famílias que residem em um território delimitado, permitindo assim, o conhecimento das condições de vida dessa população ${ }^{5}$.

Assim, os profissionais de saúde que compõem as equipe das USF encontram-se em uma posição estratégica para detectar precocemente situações potencialmente geradoras de violência intrafamiliar e as possíveis vítimas. Dessa forma, percebe-se que as crenças, informações e comunicações dos profissionais de saúde que lidam com estas situações estão embutidos de representações que repercutem na prática profissional.

Portanto, neste estudo, definiu-se como objetivo analisar a estrutura representacional de profissionais de saúde acerca da violência intrafamiliar contra idosos.

\section{Referencial Teórico-Metodológico}

Estudo com abordagem multimétodos, descritiva, exploratória, de natureza qualitativa e quantitativa. Adotou-se como caminho teórico e metodológico deste trabalho a Teoria das Representações Sociais em sua perspectiva estrutural ou também chamada de Teoria do Núcleo Central. A representação social é constituída por um conjunto de crenças, informações, opiniões e atitudes de um grupo com características semelhantes, a propósito de um dado objeto social. Esse conjunto de elementos se organiza, estrutura e se constitui em um sistema sociocognitivo de tipo específico ${ }^{6}$.

A Teoria do Núcleo Central propõe a organização das representações sociais ao redor de um núcleo central, sendo este o elemento que subsidia seu sentido fundamental e inflexível. Assim, como característica ontológica de um núcleo central de determinada representação, ressalta-se a natureza do objeto representado, o tipo de relações que o grupo mantém com este objeto e o sistema de valores e padrões sociais que constituem o ambiente de vida, em sua dimensão objetiva e subjetiva, do indivíduo e do grupo?

Compuseram a população do estudo 81 profissionais de saúde que realizavam suas atividades no cenário escolhido para a pesquisa, 16 USF do município de Jequié-BA, as quais foram selecionadas de acordo com os seguintes critérios: equipe mínima completa, segundo o preconizado pelo Ministério da Saúde; equipes com o tempo mínimo de 6 meses de implantação. Foram incluídos os profissionais com mais de 6 meses em atividade profissional no contexto do cenário escolhido pelo fator tempo configurar-se como um determinante na elaboração de representações sociais. Foram excluídos os profissionais com menos de 6 meses em atividade profissional no contexto do cenário escolhido, pelo fator tempo configurar- se como um determinante na elaboração de representações sociais.

O estudo obedeceu aos princípios éticos preconizados pela Resolução no 196/96. Obteve-se: aprovação do Comitê de Ética e Pesquisa da Universidade Estadual do Sudoeste da Bahia (CEP/UESB), sob protocolo $n^{\circ}$ 13355/2012; autorização da Secretaria Municipal de Saúde de Jequié para a execução da coleta de dados; e a assinatura do Termo de Consentimento Livre e Esclarecido por parte de cada sujeito participante. $\mathrm{O}$ período de coleta de dados ocorreu de maio a julho de 2012, em que se optou por utilizar dois instrumentos: a técnica da evocação livre de palavras e a entrevista semiestruturada.

A evocação livre de palavras é considerada uma técnica para coleta dos elementos constitutivos das representações. Tal técnica possibilita colocar em evidência a saliência e a importância hierárquica dos elementos da representação ${ }^{8}$. Também permite destacar o universo semântico do objeto estudado, assim como a sua dimensão imagética de forma mais rápida e objetiva9. A aplicação da técnica consistiu em solicitar aos sujeitos que evocassem cinco palavras ou expressões quando ouvissem o termo indutor violência intrafamiliar contra idosos, sendo as mesmas imediatamente registradas e classificadas pelos sujeitos da mais para a menos importante.

A entrevista semiestruturada permite a descrição, explicação e compreensão global de um fenômeno 
pesquisado, assim como a descrição dos conteúdos representacionais relativos a esse fenômeno, possibilitando gerar uma interface de comunicação entre o pesquisador e o informante do estudo acerca de um tema específico ${ }^{10}$.

Diante disso, foram coletadas evocações livres dos 81 sujeitos, e, entre esses, foram escolhidos, de maneira aleatória, 22 profissionais para participarem da entrevista semiestruturada. Destaca-se que a técnica de evocações foi realizada em primeiro lugar, sendo sucedida pela entrevista, no intuito de evitar que esta fosse influenciada pela entrevista.

Os vocábulos provenientes da técnica de evocações de palavras foram digitados e agrupados em ordem alfabética, gerando um dicionário que norteou a categorização das evocações, agrupando palavras com significados semelhantes. $\mathrm{O}$ produto das evocações foi organizado previamente, constituindo um corpus para análise.

O material foi, então, tratado pelo software EVOC (versão 2003), que possibilita efetuar a organização dos termos produzidos em função da hierarquia subjacente à frequência e à ordem média de evocação $(\mathrm{OME})$ e favorece a construção da figura/quadro de quatro casas. O programa calcula e informa para o conjunto do corpus, a frequência simples e as ordens médias de evocação de cada palavra e a média das ordens médias de evocação ou rang ${ }^{9}$ que, neste estudo, obedeceu a ordem média de importância (OMI) atribuída pelos sujeitos.

A utilização do programa gerou relatórios que possibilitaram a construção do figura/quadro de quatro casas, proposto por Vergès ${ }^{11}$. Essa técnica, ao combinar dois atributos relacionados às palavras ou às expressões evocadas, que são a frequência e a ordem em que foram evocadas ou hierarquizadas, possibilita a distribuição dos termos produzidos segundo a importância atribuída pelos sujeitos ${ }^{9}$.

A figura de quatro casas corresponde a quatro quadrantes com quatro conjuntos de termos. No quadrante superior esquerdo ficam situados os termos verdadeiramente significativos para os sujeitos e que constituem, provavelmente, o núcleo central da representação estudada. $\mathrm{O}$ quadrante superior direito denomina-se como primeira periferia; no quadrante inferior esquerdo, localizam-se os elementos de contraste; e as palavras localizadas no quadrante inferior direito constituem a segunda periferia da representação $\mathrm{O}^{7,8,12}$.

Os dados provenientes das entrevistas foram analisados de acordo com a técnica de análise de conteúdo temática, segundo Bardin ${ }^{13}$. É importante ressaltar que o procedimento quantitativo utilizado neste estudo restringiu-se ao tratamento estatístico realizado com os dados obtidos através da técnica de evocações livres de palavras. Entretanto, os seus resultados foram analisados qualitativamente assim como os discursos que emergiram da entrevista semiestruturada. Os depoimentos dos sujeitos do estudo foram identificados com a inicial maiúscula da categoria profissional. Exemplo, sigla ACS, no caso de agente comunitário de saúde, seguida de um algarismo arábico.

\section{Resultados e Discussão}

Os sujeitos foram $22(27,1 \%)$ agentes comunitários de saúde (ACS); 22 (27,1\%) auxiliares/técnicas de enfermagem (A/T); 21 (25,9\%) enfermeiros (E); 7 (8,6\%) médicos (M); 5 (6,1\%) odontólogos (O) e 4 (4,9\%) atendentes de consultório dentário (ACD).

A análise do corpus formado pelas evocações de 81 informantes revelou que, em resposta ao termo indutor violência intrafamiliar contra idosos, foram evocadas 394 palavras, sendo 115 diferentes. O rang, ou seja, a média das ordens médias de importância foi de 3,0, enquanto a frequência média foi de 11 e a mínima, 5 .

O cruzamento da frequência média das palavras evocadas com a média das suas ordens médias de importância permitiu distribuir as evocações na figura de quatro casas, que possibilita observar os conteúdos da representação social, bem como a estrutura e a hierarquia de seus elementos, conforme mostra a Figura 1.

Observa-se no quadrante superior esquerdo o possível núcleo central da representação da violência intrafamiliar contra idosos para os profissionais das USF. Nesse quadrante, evidenciam-se as seguintes palavras: desamor, maus tratos e desrespeito. Estas se assemelham por serem as mais evocadas e hierarquizadas nos primeiros lugares, apresentando frequência superior a 11, além das OMI serem inferiores a 3,0, sendo as escolhidas pelos sujeitos como mais importantes na hierarquia das palavras.

É importante destacar que o núcleo central é determinado pela natureza do objeto representado, pelas relações que o grupo mantém com esse objeto e pelo sistema de valores e normas que norteiam o meio ambiente ideológico do momento e do grupo. São seus elementos que estabilizam e fornecem sentido às representações construídas pelos indivíduos ${ }^{6}$.

Diante disso, os possíveis elementos constituintes do núcleo central indicam as seguintes dimensões: afetiva (desamor), atitudinal (desrespeito) e comportamental (maus tratos). Essas dimensões se desdobram nos demais quadrantes, evidenciando uma organização semântica dos distintos elementos que constituem a representação social do objeto em estudo.

$\mathrm{Na}$ primeira periferia (quadrante superior direito) encontram-se os termos agressão, desarmonia e desumano, refletindo as dimensões comportamental (agressão), atitudinal (desumano) e afetiva (desarmonia). Já os elementos da segunda periferia (quadrante inferior direito) sugerem a presença de uma dimensão imagética (droga-financeiro-solidão), atitudinal (descaso-descuido-incompreensão-ingratidão-irre- 


\begin{tabular}{|c|c|c|c|c|c|}
\hline \multicolumn{3}{|c|}{ Elementos centrais } & \multicolumn{3}{|c|}{ Elementos primeira periferia } \\
\hline \multicolumn{3}{|c|}{ Frequência média $>=11 / \mathrm{OMI}<=3,0$} & \multicolumn{3}{|c|}{ Frequência média $>=11 / \mathrm{OMI}>=3,0$} \\
\hline $\begin{array}{l}\text { Desamor } \\
\text { Maus tratos } \\
\text { Desrespeito }\end{array}$ & $\begin{array}{c}\text { Freq } \\
38 \\
23 \\
22\end{array}$ & $\begin{array}{l}\text { Rang } \\
1,68 \\
2,30 \\
2,81\end{array}$ & $\begin{array}{l}\text { Desarmonia } \\
\text { Desumano } \\
\text { Agressão }\end{array}$ & $\begin{array}{c}\text { Freq } \\
16 \\
15 \\
11\end{array}$ & $\begin{array}{l}\text { Rang } \\
3,87 \\
3,26 \\
3,45\end{array}$ \\
\hline \multicolumn{3}{|c|}{ Elementos de contraste } & \multicolumn{3}{|c|}{ Elementos segunda periferia } \\
\hline \multicolumn{3}{|c|}{ Frequência média $<=11 / \mathrm{OMI}<=3,0$} & \multicolumn{3}{|c|}{ Frequência média $<=11 / \mathrm{OMI}>=3,0$} \\
\hline $\begin{array}{l}\text { Cuidado } \\
\text { Falta de atenção } \\
\text { Falta de Deus } \\
\text { Violência }\end{array}$ & $\begin{array}{l}6 \\
6 \\
5 \\
5\end{array}$ & $\begin{array}{l}1,66 \\
2,16 \\
2,60 \\
2,80\end{array}$ & $\begin{array}{l}\text { Descaso } \\
\text { Descuido } \\
\text { Maldade } \\
\text { Financeiro } \\
\text { Injustiça } \\
\text { Irresponsabilidade } \\
\text { Droga } \\
\text { Incompreensão } \\
\text { Ingratidão } \\
\text { Solidão }\end{array}$ & $\begin{array}{c}10 \\
10 \\
10 \\
9 \\
9 \\
6 \\
5 \\
5 \\
5 \\
5\end{array}$ & $\begin{array}{l}3,10 \\
3,20 \\
3,30 \\
3,44 \\
3,55 \\
3,50 \\
3,20 \\
3,20 \\
3,20 \\
3,60\end{array}$ \\
\hline
\end{tabular}

FIGURA 1: Quadro de quatro casas das evocações dos profissionais das unidades de saúde da família ao termo indutor violência intrafamiliar contra idosos. Jequié-BA, 2012.

sponsabilidade) e comportamental (injustiça-maldade) da violência intrafamiliar contra idosos. Sendo assim, observa-se um sistema periférico que integra as experiências e as histórias individuais dos atores sociais, apresentando-se sensível ao contexto social imediato, mas também se mostra flexível, permitindo adaptação à realidade experimentada pelos profissionais ${ }^{14}$.

Entre os elementos de contraste (quadrante inferior esquerdo) foram evocadas as seguintes palavras: cuidado, falta de atenção, falta de Deus e violência. Essas palavras foram escolhidas pelos sujeitos como mais importantes na hierarquia dos termos produzidos, no entanto, em função das frequências abaixo da média, não estão inseridas no âmbito do núcleo central. Observam-se, nesse espaço da estrutura da representação, três dimensões: atitudinal (falta de atenção), afetiva (falta de Deus) e comportamental (violência).

Nesse contexto, ao analisar os resultados mencionados, pode-se afirmar que os sujeitos apresentam uma representação negativa da violência intrafamiliar contra idosos, associada a quatro dimensões: afetiva, atitudinal, comportamental e imagética.

$\mathrm{Na}$ dimensão afetiva, a palavra desamor apresentou a maior frequência (38) das evocações, sendo a segunda mais prontamente hierarquizada de todo o conjunto $(1,68)$, manifestando-se como o componente mais importante do núcleo central, revelando que os sujeitos assentaram as raízes desta representação neste elemento. Essa dimensão apresenta-se desdobrada na segunda periferia por meio da palavra desarmonia, e nos elementos de contraste por meio do léxico falta de Deus.

Desse modo, esta dimensão encontra-se ancorada em elementos que refletem os conflitos existentes nas relações familiares, os quais podem gerar situações de violência. Ao mesmo tempo, observa-se a influência da religiosidade na ancoragem desta representação, quando os profissionais reportam a ausência divina permeando as manifestações da violência intrafamiliar contra idosos.

Pode-se inferir que a ocorrência de situações de violência familiar contra idosos revela conflitos familiares anteriores que se expressam em forma de violência. Portanto, se há violência é porque há conflito; pode até haver amor, porém é um amor conflituoso ${ }^{15}$.

Por outro lado, a dimensão atitudinal aparece objetivada em expressões como desrespeito, descuido, irresponsabilidade, incompreensão, ingratidão, falta de atenção, desumano e descaso. Esta dimensão retrata as atitudes negativas de familiares para com os idosos, que se traduzem em manifestações de violação dos direitos assegurados por lei, abuso psicológico e pouca ou nenhuma responsabilidade no suprimento das necessidades dessa população. Essas manifestações são corroboradas nos depoimentos dos profissionais.

[...] desrespeito com o idoso [...], de achar que não tinha direito de se responsabilizar por ele, [...] de achar que não tinha que ter o cuidado com ele [...] ele já tem 90 e poucos anos de idade, já está com uma deficiência bastante alta. (E1)

\section{[...] Falta de paciência com o idoso, xingamentos [...]. (E76)}

Nesse cenário, a violência intrafamiliar contra o idoso torna-se um problema importante, particularmente com o crescente envelhecimento da população, acompanhado de uma baixa cobertura de cuidados de saúde a longo prazo e da disponibilidade de cuidadores 
familiares para estes idosos ${ }^{16}$. A esse contexto somam-se as novas formas de arranjos domiciliares e o estresse da vida moderna, proporcionando à família, ao Estado e à sociedade importantes desafios a serem enfrentados.

O léxico desumano apresenta-se interligado com os termos injustiça e maldade, que aparecem na segunda periferia da representação, expressando atitudes que estão embutidas no fenômeno da violência, revelando a desvalorização social da pessoa idosa, iniciada no contexto familiar. Tal contexto foi elucidado nos relatos dos informantes.

[...] porque deixa de ser um ser humano, tratado como ser humano, para ser um ser humano tratado como lixo, porque até um animal tem liberdade de ir e vir, eles deixam solto, e o idoso acamado não [...] ele não tem como sair dali, ele é refém de sua própria família [...]. (ACS61)

A dimensão comportamental se expressa em elementos concretos relacionados a à violência intrafamiliar, como maus tratos, que aparece no núcleo central com a segunda maior frequência de toda análise (23), e o elemento de contraste violência, que faz parte do termo indutor da representação em estudo. Por outro lado, o termo maus tratos também está relacionado às diversas demonstrações de negligência contra idosos, que os profissionais da estratégia saúde da família (ESF) identificam no cotidiano de muitas famílias. Do mesmo modo, essas manifestações são evidenciadas nas falas dos sujeitos.

[...] falta de alimentação ao idoso na hora correta [...] deixa o idoso muito tempo sem tomar banho, com a fralda, deixa o idoso com fome, dá medicação na hora errada, esse tipo de coisa [...] Na questão da higiene porque eles não querem cuidar, deixa o quarto sujo, escuro, fedendo [...]. (ACS61)

Ainda nessa dimensão, o elemento agressão, que aparece na primeira periferia juntamente com a palavra desumano, é um termo que remete a um tipo específico de violência intrafamiliar contra idosos, a violência física. Observa-se nas falas dos informantes a manifestação da agressão física contra idosos praticadas por familiares, no contexto das USF, evidenciando o contato dos profissionais com essas situações.

[...] filho que espancou uma mãe [...] ele bateu e a paciente chegou aqui com problema e aí chamou a polícia, a polícia veio, e aí ele fingiu que era outra pessoa, sendo ele que tinha agredido a mãe [...]. (E70)

No Brasil, é comum a coabitação entre diferentes gerações, como reflexo do envelhecimento populacional e das mudanças nas configurações familiares. A coabitação intensifica o convívio intergeracional, com diferentes valores partilhados, o que pode resultar em um contexto favorável para o estabelecimento de conflitos no espaço domiciliar que, muitas vezes, resultam em violência contra os idosos ${ }^{17}$.
No que se refere à dimensão imagética, presente apenas no quadrante inferior direito na periferia da representação, pode-se dizer que as palavras droga, financeiro e solidão ilustram fatores contribuintes para a ocorrência da violência intrafamiliar contra os idosos, os quais estão presentes no cotidiano dos profissionais. Exigem destes, além de uma atenção especial para com essa população, o desenvolvimento de estratégias de prevenção no contexto familiar e social da comunidade sob sua responsabilidade. Dessa forma, destaca-se que as representações atuam como guia para as práticas, bem como para as ações e as relações sociais ${ }^{14}$.

Nesse contexto, os termos descaso e solidão refletem a responsabilidade da família no abandono dos idosos, expondo-os a situações ameaçadoras de sua proteção e segurança. Essa realidade foi referida nos discursos dos sujeitos.

[...] deixando o idoso sozinho, já chegou ao ponto até da casa pegar fogo e os vizinhos terem que arrombar a porta para tirar o idoso [...]. (ACS50)

Desse modo, é importante ressaltar que a construção da violência contra os idosos é determinada por multifatores, que conduzem tanto a vítima quanto o agressor a um ambiente hostil, onde se desenvolve a violência. Nesse sentido, destaca-se na dimensão imagética, a presença do léxico droga, o qual retrata um problema social cada vez mais presente no contexto das USF, que é a presença de álcool e outras drogas no contexto familiar interferindo no seu funcionamento. Os informantes relataram a identificação desse problema como fator predisponente à ocorrência da violência intrafamiliar contra idosos.

[...] filho usar o dinheiro do idoso para beber, encher a casa de pessoas para beber e até usar outras coisas, e o velhinho, lá, sujo, todo maltratado [...]. (ACS50)

Portanto, enfatiza-se que a utilização indevida do álcool e drogas se torna um agente potencializador para a ocorrência desses eventos no seio da famíliaa ${ }^{18}$. Em estudo retrospectivo, realizado com dados obtidos no Sistema de Informação de Agravos de Notificação - versão Net (SINAN Net), abrangendo as notificações de violência doméstica, sexual e/ou outras violências na população de idosos, a violência física, negligência e abuso sexual foram relacionados ao consumo de álcool pelos agressores ${ }^{19}$.

Ainda nessa dimensão, a palavra financeiro reflete um dos fortes motivos da violência intrafamiliar contra idosos, que são as questões de ordem econômica. Nesse sentido, os depoimentos retrataram manifestações de violência financeira contra idosos no contexto familiar:

[...] explora, tem ele em casa, como fonte de renda [...] não utiliza desta renda para tratamento do próprio idoso, falta até mesmo medicação. (ACS16)

[...] muitas vezes o idoso que é o provedor, não só dos filhos, como dos netos e às vezes dos bisnetos [...]. (E71) 
Dessa forma, observa-se que a dependência relatada pelos entrevistados pode contribuir para acirrar conflitos e gerar comportamentos violentos, pois o idoso é o responsável financeiro, no entanto está sob a custódia e a responsabilidade da família ${ }^{18}$. Nota-se a exploração financeira acompanhada por manifestações de negligência. Situações que marcam o abuso financeiro contra o idoso vão ao encontro de pesquisa realizada com profissionais atuantes na atenção primária à saúde, cujos achados revelaram que o idoso é privado de seus recursos em proveito dos familiares, manifestação frequentemente observada, aumentando sua vulnerabilidade a situações conflituosas e com potencial de risco para a violência ${ }^{20}$.

É interessante destacar a presença do léxico cuidado como elemento de contraste na estrutura representacional, que apesar de possuir baixa frequência (6), foi a palavra hierarquizada em primeiro lugar, apresentando o menor rang de toda a análise $(1,66)$. Destaca-se que, em uma representação caracteristicamente negativa, a presença de um elemento positivo nessa zona aponta a existência de um subgrupo de profissionais que salienta a necessidade de cuidado com o idoso, como forma de compensação ou equilíbrio da violência efetivamente desenvolvida no seio familiar.

Nesse sentido, ressalta-se que o relacionamento interpessoal entre o profissional, o idoso e a família, representando o cuidado em saúde praticado por esse profissional pode se revelar importante no cotidiano assistencial desse grupo.

Nesse contexto, ressalta-se que a equipe da ESF, ao adentrar o domicílio do idoso/família, deve promover o cuidado com ações direcionadas para as suas necessidades de saúde, contemplando as suas especificidades, mas também da família como um todo. E ainda, é importante destacar que o enfrentamento da violência pelos serviços de saúde requer o desenvolvimento de ações intersetoriais, não se limitando a ações isoladas, pautadas na linearidade, com articulação da área da saúde e outros serviços ${ }^{21}$.

Nesse contexto, estudo revela que a abordagem da violência familiar por profissionais da atenção primária envolve não apenas a discussão da temática no cotidiano dos serviços de saúde, em capacitação profissional e interdisciplinaridade, como também o estabelecimento de ações intersetoriais ${ }^{22}$.

\section{ConClusão}

A representação social do grupo estudado sobre a violência intrafamiliar contra idosos apresenta-se caracteristicamente negativa, sustentada pelas dimensões: afetiva, atitudinal, comportamental e imagética, retratando, assim, a construção simbólica desses profissionais no cotidiano de trabalho das USF, diante desse fenômeno de múltiplas facetas.
As representações deixam evidente um cenário de diferentes manifestações de violência contra idosos, praticadas por familiares, tais como as agressões físicas e psicológicas, negligência, exploração financeira e abandono. Nesse sentido, o conhecimento desta representação poderá possibilitar melhor direcionamento na elaboração de estratégias de promoção e prevenção da violência no contexto familiar e social das USF por profissionais e gestores.

Sendo assim, os resultados deste estudo podem servir de subsídios para os profissionais das mais diversas áreas que estão comprometidos com o enfrentamento desta problemática.

Precisa-se ampliar o olhar sobre o fenômeno da violência intrafamiliar contra idosos e repensar ações mais efetivas, não somente na perspectiva políticoeconômico-social, mas englobando a dimensão da saúde coletiva e de enfermagem.

O presente estudo foi realizado em um contexto da atenção básica, especificamente, na ESF, e por isso, possui limitações quanto à generalização dos resultados, em face da natureza qualitativa adotada. Em adição, aponta trajetórias para que novas pesquisas possam explorar, em outros cenários e contextos, a presença da violência intrafamiliar contra idosos no plano do pensamento social. Dessa forma, é pertinente que novos estudos acerca dessa temática sejam realizados.

\section{REFERÊNCIAS}

1.Instituto de Pesquisa Econômica Aplicada (IPEA). Tendências demográficas mostradas pela PNAD 2011. Rio de Janeiro: Comunicados do IPEA; 2012.

2.Oliveira MAS, Menezes TMO. A enfermeira no cuidado ao idoso na estratégia saúde da família: sentidos do vivido. Rev enferm UERJ. 2014; 22:513-8.

3.Organização Mundial da Saúde. Relatório mundial violência e saúde. Genebra (Swi): OMS; 2002.

4.Moraes CL, Aparatto Junior PC, Reichenheim ME. Rompendo o silêncio e suas barreiras: um inquérito domiciliar sobre a violência doméstica contra idosos em área de abrangência do Programa Médico de Família de Niterói, Rio de Janeiro, Brasil. Cad Saúde Pública. 2008; 24: 2289-300.

5.Rosana A. Conhecendo o território. In: Aquino R, organizadores. Manual para treinamento introdutório das equipes de saúde da família. Salvador (BA): Pólo de Capacitação, Formação e Educação Permanente de Pessoal para Saúde da Família; 2001.

6.Abric JC. A abordagem estrutural das representações sociais. In: Moreira ASP, Oliveira DC, organizadoras. Estudos interdisciplinares de representação social. Goiânia (GO): AB Editora; 2000. p. 27-38.

7.Gomes AMT, Oliveira DC. A estrutura representacional de enfermeiros acerca da enfermagem: novos momentos e antigos desafios. Rev enferm UERJ. 2007; 15: $168-75$. 
8.Sá CP. Núcleo central das representações sociais. Petrópolis (RJ): Editora Vozes; 1996.

9.Oliveira DC, Marques SC, Gomes AMT, Teixeira MCTV. Análise das evocações livres: uma técnica de análise estrutural das representações sociais. In: Paredes AS. Perspectivas teórico-metodológicas em representações sociais. João Pessoa (PB): Editora Universitária UFPB; 2005. p. 573- 603.

10.Triviños ANS. Introdução à pesquisa em ciências sociais: a pesquisa qualitativa em educação. São Paulo: Atlas; 2009.

11.Vergès P. Approche du noyau central: propriétés quantitatives et structurales. In: Guimelli C. Structures et transformations des représentations sociales. Lausanne (Swi): Delachaux et Niestlé; 1994. p. 233-54.

12.Reis AT, Oliveira DC, Gomes AMT. Representações sociais sobre saúde entre adolescentes de escolas públicas do município do Rio de Janeiro. Rev enferm UERJ. 2009; 17: 473-8.

13.Bardin L. Análise de Conteúdo. Lisboa ( Pt): Edições 70; 2010 .

14.Oliveira DC, Gomes AMT, Pontes APM, Salgado LPP. Atitudes, sentimentos e imagens na representação social da sexualidade entre adolescentes. Esc Anna Nery. 2009; 13: 817-23.

15.Goldfarb DC. Pensando nas origens da violência. Ciênc saúde coletiva. 2010; 15: 2669-76.
16. Jackson JL, Mallory R. Aggression and violence among elderly patients, a growing health problem. J Gen Intern Med.2009; 24: 1167-8.

17.Abath MB, Leal MCC, Melo Filho DA. Fatores associados à violência doméstica contra a pessoa idosa. Rev Bras Geriatr Gerontol.2012; 15(2): 305-14 .

18.Santos ACPO, Silva CA, Carvalho LS, Menezes MR. A construção da violência contra idosos. Rev Bras Geriatr Gerontol. 2007; 10: 129-40.

19.Mascarenhas MDM, Andrade SSCA, Neves ACM, Pedrosa AAG, Silva MM, Malta DC. Violência contra a pessoa idosa: análise das notificações realizadas no setor saúde - Brasil, 2010. Ciênc saúde coletiva. 2012; 17: 2331-41.

20.Wanderbroocke ACNS, Moré CLOO. Significados de violência familiar contra o idoso na perspectiva de profissionais da atenção primária à saúde. Ciênc saúde coletiva; 2012; 17 (8): 2095-103.

21.Gomes NP, Bomfim ANA, Diniz NMF, Souza SS, Couto TM. Percepção dos profissionais da rede de serviços sobre o enfrentamento da violência contra a mulher. Rev enferm UERJ. 2012; 20:173-8.

22.Lobato GR, Moraes CL, Nascimento MC. Desafios da atenção à violência doméstica contra crianças e adolescentes no Programa Saúde da Família em cidade de médio porte do Estado do Rio de Janeiro, Brasil. Cad Saúde Pública 2012;28:1749-58. 